\title{
Association of macrosomia with perinatal and postneonatal mortality among First Nations people in Quebec
}

\author{
Spogmai Wassimi MS, Russell Wilkins MUrb, Nancy G.L. Mchugh MS, Lin Xiao MS, Fabienne Simonet MS, \\ Zhong-Cheng Luo MD PhD
}

See related commentary by Gray-Donald, page 295

Competing interests: None declared.

This article has been peer reviewed.

Correspondence to: Dr. Zhong-Cheng Luo, zhong-cheng.luo@ recherche-ste-justine.qc.ca

CMAJ 2011. DOI:10.1503 /cmaj.100837

\section{Abstract}

Background: High prevalence of infant macrosomia (up to $36 \%$, the highest in the world) has been reported in some First Nations communities in the Canadian province of Quebec and the eastern area of the province of Ontario. We aimed to assess whether infant macrosomia was associated with elevated risks of perinatal and postneonatal mortality among First Nations people in Quebec.

Methods: We calculated risk ratios (RRs) of perinatal and postneonatal mortality by birthweight for gestational age, comparing births to First Nations women $(n=5193)$ versus women whose mother tongue is French ( $n=653424$, the majority reference group) in Quebec 1991-2000.

Results: The prevalence of infant macrosomia (birthweight for gestational age > 90th percentile) was $27.5 \%$ among births to First Nations women, which was 3.3 times (confi- trend toward higher birthweights has emerged in recent decades. ${ }^{1-3}$ Reflected in this trend is a rise in the prevalence of infant macrosomia, commonly defined as either a birthweight greater than $4000 \mathrm{~g}$ or a birthweight for gestational age greater than the 90th percentile relative to a fetal growth standard. ${ }^{4-8}$ Maternal obesity, impaired glucose tolerance and gestational diabetes mellitus are important risk factors for infant macrosomia ${ }^{9,10}$ and are known to afflict a much higher proportion of people in Aboriginal populations than in the general population. ${ }^{11-14}$ This is true especially for Aboriginal populations in which a traditional lifestyle has changed to a less physically active, modern lifestyle in recent decades. A high prevalence of infant macrosomia (up to $36 \%$, which, to the best of our knowledge, is the highest in the world) has been reported in some First Nations communities of Quebec and eastern Ontario in Canada. ${ }^{15-17}$ However, little is dence interval $[\mathrm{Cl}] 3.2-3.5)$ higher than the prevalence $(8.3 \%)$ among births to women whose mother tongue is French. Risk ratios for perinatal mortality among births to First Nations women were $1.8(95 \% \mathrm{Cl}$ 1.3-2.5) for births with weight appropriate for gestational age, 4.1 (95\% Cl 2.4-7.0) for small-for-gestational-age $(<10$ th percentile) births and $<1$ (not significant) for macrosomic births compared to births among women whose mother tongue is French. The RRs for postneonatal mortality were $4.3(95 \% \mathrm{Cl}$ 2.7-6.7) for infants with appropriate-for-gestational-age birthweight and $8.3(95 \% \mathrm{Cl} 4.0-17.0)$ for infants with macrosomia.

Interpretation: Macrosomia was associated with a generally protective effect against perinatal death, but substantially greater risks of postneonatal death among births to First Nations women in Quebec versus women whose mother tongue is French. known about the implications of this high prevalence for perinatal and infant health of First Nations people in these regions. We examined whether infant macrosomia was associated with increased risk for perinatal and postneonatal death among First Nations infants in Quebec.

\section{Methods}

\section{Data source and inclusion criteria}

We conducted an analysis of perinatal and infant mortality by birthweight for gestational age in a cohort of births to women with a First Nations mother tongue $(n=5193)$ and a majority reference group of women whose mother tongue is French $(n=653424)$ in the province of Quebec from 1991 to 2000.

We used linked data from Statistics Canada on birth and infant deaths. We restricted our analysis to births that occurred at a gestational age of 20 
weeks or later and birthweights of $500 \mathrm{~g}$ or more. Births for which data on birthweight or gestational age were missing $(0.8 \%)$ were excluded because fetal growth could not be assessed.

We used maternal mother tongue as recorded on birth registrations to identify births to First Nations women. This method is thought to identify about $50 \%-60 \%$ of all births to First Nations women in Quebec. ${ }^{18}$ By design, the study excluded births to women with an Inuit mother tongue (92\% of self-identified Inuit in Quebec reported Inuktitut or Inuit language as their mother tongue, according to the 2001 census), a population known to have much higher perinatal and postneonatal mortality compared to nonAboriginal populations. ${ }^{18,19}$

We used data for the period of 1991 to 2000 because they were the most recent linked data available at the time the study protocol was approved by the research ethics board and because the linked vital records of more recent years do not allow for identification of First Nations women reporting multiple mother tongues (i.e., French or English plus an Aboriginal language becomes French or English plus other).

Informed consent was not sought from individual participants because the study was based on anonymized, linked birth data. The study was approved by the research ethics board of SainteJustine Hospital, University of Montreal, and by the First Nations of Quebec and Labrador Health and Social Services Commission.

\section{Outcomes}

Primary outcomes were perinatal and postneonatal death. Perinatal death included stillbirths (fetal deaths at $\geq 20$ weeks of gestation or later with weight of greater than $500 \mathrm{~g}$ ) plus neonatal deaths (0-27 days postnatally). Postneonatal death included any death between 28 days of postnatal life and the child's first birthday. We chose perinatal death as a primary outcome because it would not have been affected by variability in the registration of births at the borderline of viability (i.e., variable judgments by individual physicians could have resulted in such deaths being registered as either stillbirths or neonatal deaths). ${ }^{20}$

\section{Statistical analysis}

Two dimensions of comparisons were made. First, we calculated the risk ratio (RR) and 95\% confidence intervals (CIs) for perinatal and postneonatal death, comparing births to First Nations women versus women whose mother tongue was French by birthweight for gestational age according to the Canadian sex-specific fetal growth standards ${ }^{21}$ (small for gestational age = $<10$ th percentile, appropriate for gestational age $=10$ th-90th percentile, and large for gestational age $=>90$ th percentile, or macrosomic). Second, we calculated the RRs $(95 \%)$ for perinatal and postneonatal death comparing macrosomic versus weight appropriate-for-gestational-age infants within the First Nations and French-asmother-tongue groups. We also calculated the RRs for postneonatal mortality due to sudden infant death syndrome (SIDS). Other cause-specific death risks were not calculated because the numbers were too small for First Nations births. Crude RRs by birthweight for gestational age categories were presented because our objective

Table 1: Perinatal and postneonatal mortality* by birthweight for gestational age among births in Quebec to First Nations women and women whose mother tongue is French, 1991-2000

\begin{tabular}{|c|c|c|c|}
\hline $\begin{array}{l}\text { Birthweight for gestational } \\
\text { age, percentile }\end{array}$ & $\begin{array}{l}\text { First Nations* } \\
\text { per } 1000 \text { (n/total) }\end{array}$ & $\begin{array}{l}\text { French mother tongue* } \\
\text { per } 1000 \text { ( } n \text { /total) }\end{array}$ & $\begin{array}{l}\text { First Nations v. French } \\
\text { mother tongue RR }(95 \% \mathrm{Cl})\end{array}$ \\
\hline \multicolumn{4}{|l|}{ Perinatal death } \\
\hline$<10$ th & $69.5(13 / 187)$ & $16.9(1193 / 70736)$ & $4.12(2.43-6.98)$ \\
\hline 10th-90th & $9.2(33 / 3575)$ & $5.2(2759 / 528517)$ & $1.77(1.26-2.49)$ \\
\hline$>90$ th & $4.9(7 / 1431)$ & $8.0(435 / 54$ 179) & $0.61(0.29-1.28)$ \\
\hline \multicolumn{4}{|l|}{ Postneonatal death } \\
\hline 10th-90th & $5.4(19 / 3542)$ & $1.3(659 / 525758)$ & $4.28(2.72-6.74)$ \\
\hline$>90$ th & $6.3(9 / 1424)$ & $0.8(41 / 53744)$ & $8.28(4.03-17.01)$ \\
\hline \multicolumn{4}{|l|}{ Postneonatal SIDS } \\
\hline 10th-90th & $1.7(6 / 3542)$ & $0.4(198 / 525758)$ & $4.50(2.00-10.13)$ \\
\hline$>90$ th & $2.1(3 / 1424)$ & $0.2(9 / 53744)$ & $12.58(3.41-46.42)$ \\
\hline \multicolumn{4}{|c|}{$\begin{array}{l}\text { Note: } \mathrm{Cl}=\text { confidence interval, } \mathrm{RR}=\text { risk ratio, SIDS = sudden infant death syndrome. } \\
\text { * Data for outcome rates are per } 1000 \text { total births for perinatal death and per } 1000 \text { postneonatal survivors for postneonatal } \\
\text { death. Results in the category of birthweight for gestational age }<10 \text { th percentile were not presented for postneonatal death } \\
\text { because values for the First Nations group were too small (one death) for meaningful comparisons. }\end{array}$} \\
\hline
\end{tabular}


was to describe the effects of fetal growth on perinatal and postneonatal mortality. Various risk factors could have affected the risks of death through affecting fetal growth (on the causal pathway). No information was available on medical risk factors such as diabetes in pregnancy in the Canadian linked birth data. Because remoteness may affect timely access to high-quality tertiary care and hence the risks of perinatal and postneonatal death, ${ }^{22}$ we further assessed the risk differences restricted to remote areas. We defined remote areas as any rural area with a workforce-commuting flow into urban centres (population $\geq 10000$ in the 1996 census) of less than $5 \%$ based on maternal residential postal codes as recorded on birth registrations. ${ }^{22}$

Two-tailed $p$ values $<0.05$ were considered significant.

\section{Results}

The prevalence of infant macrosomia was $27.5 \%(1431 / 5193)$ for births to First Nations women, or 3.3 times the prevalence of $8.3 \%$ (54 192/653 424) for macrosomic births to women whose mother tongue is French $(p<0.001)$. The prevalence of preterm birth ( $<37$ completed weeks of gestation) was similar for all births $(6.6 \% \mathrm{v} .7 .3 \%)$ and for macrosomic births $(6.4 \%$ v. $6.6 \%)$ to First Nations women versus women whose mother tongue is French (all $p>0.05)$. Perinatal mortality (7.3 v. 6.1 per $1000)$ and postneonatal mortality (1.7 v. 1.2 per 1000) were significantly higher for male versus female infants $(p<0.001)$, with a similar proportion of male infants for births to First Nations women $(50 \%)$ versus women whose mother tongue is French (51\%).

Perinatal mortality among births to First Nations women was 1.5 times higher than among births to women whose mother tongue is French (10.2 per 1000 [53/5193] v. 6.7 per 1000 [4387/653 424], $p<0.001)$, and postneonatal mortality was 3.9 times higher $(5.6$ per 1000 [29/5193] v. 1.4 per 1000 [940/653 424]). Peri-

\begin{tabular}{|c|c|c|}
\hline Variable & $\begin{array}{l}\text { First Nations, } \\
\text { RR }(95 \% \mathrm{Cl})\end{array}$ & $\begin{array}{c}\text { French mother tongue, } \\
\text { RR }(95 \% \mathrm{Cl})\end{array}$ \\
\hline Perinatal death & $0.53(0.24-1.20)$ & $1.54(1.39-1.70)$ \\
\hline Postneonatal death & $1.18(0.53-2.60)$ & $0.61(0.44-0.83)$ \\
\hline Postneonatal SIDS & $1.24(0.31-4.97)$ & $0.44(0.23-0.87)$ \\
\hline
\end{tabular}

natal mortality was 1.8 times higher for births with appropriate-for-gestational-age birthweight and 4.1 times higher for those with small-forgestational-age birthweight (all $p<0.001$ ), but not significantly lower for macrosomic births (Table 1). The RR for postneonatal death among infants of First Nations women versus women whose mother tongue is French was about 4.3 for infants with appropriate-for-gestational-age birthweight and was much greater $(R R=8.3)$ for macrosomic infants (all $p<0.001$ ). The RR for postneonatal SIDS was 4.5 among infants with appropriate-for-gestational-age birthweight and was much greater $(\mathrm{RR}=12.6)$ among macrosomic infants (all $p<0.001$ ).

When compared to appropriate-for-gestational-age births, perinatal mortality among macrosomic births was significantly higher for women whose mother tongue is French $(p<0.001)$, but nonsignificantly lower for First Nations women (Table 2). Postneonatal mortality among macrosomic births versus weightappropriate-for-gestational-age births was significantly lower for women whose mother tongue is French $(\mathrm{RR}=0.61, p<0.001)$, but a significant difference was not observed $(\mathrm{RR}=1.2, p>0.68)$ among infants of First Nations women.

The proportion of births to mothers residing in remote areas was substantially higher for First Nations women $(69 \%, 3607 / 5193)$ versus women whose mother tongue is French (5\%, 35 705/653 424). Comparing births to First Nations women versus women whose mother tongue is French living in remote areas, perinatal mortality was substantially higher for small-forgestational-age infants (81.8 v. 18.7 per 1000 , $\mathrm{RR}=4.4, p<0.001)$, and postneonatal mortality was substantially higher for macrosomic infants (66.2 v. 7.2 per $1000, \mathrm{RR}=9.0, p<0.01)$. The RRs for both comparisons were similar to those observed in the overall analyses.

\section{Interpretation}

\section{Main findings}

We found that macrosomia was not associated with increased risk of perinatal death among births to First Nations women in Quebec, although its prevalence was three times higher than among births to women whose mother tongue is French. Macrosomia was associated with a much greater risk of postneonatal death among infants of First Nations women versus women whose mother tongue is French.

Our data confirmed the high prevalence of infant macrosomia among births to First Nations women, ${ }^{15,23}$ and the higher perinatal and postneonatal mortality among births to First Nations 
women in Quebec versus women whose mother tongue is French. ${ }^{18}$ However, the elevated risk for postneonatal mortality $(\mathrm{RR}=3.9)$ was smaller than that for births in Inuit-inhabited versus other areas of Canada $(\mathrm{RR}=6.2) .{ }^{19}$

How such disparities in mortality may differ for infants with poor or excessive fetal growth has not been explored. Our results show that elevation of risk varied substantially by fetal growth. Among births to First Nations women, small-for-gestational-age infants were at much higher risk for perinatal death $(\mathrm{RR}=4.1)$ versus those born to women whose mother tongue is French, indicating a need for improved access to high-quality perinatal care for such high-risk deliveries to First Nations women, especially those living in remote areas. (Most of the First Nations women in our study lived in remote communities.) By contrast, macrosomic births to First Nations women were not at higher risk for perinatal death compared with such births to women whose mother tongue is French or compared with births of infants with appropriate-forgestational-age birthweight among First Nations women. Macrosomia seemed somewhat protective against perinatal death among births to First Nations women. By contrast, macrosomia was associated with an increased risk of perinatal death among births to women whose mother tongue is French.

Macrosomia was associated with a significantly lower risk of postneonatal death among infants of women whose mother tongue is French but not First Nations women. It is unclear why macrosomia was protective against postneonatal death among infants of women whose mother tongue is French; we are unaware of such an effect reported in other populations. Although the risks for postneonatal death and SIDS were higher for macrosomic infants among First Nations versus French-as-mother-tongue groups, our study's within-group comparisons could not detect a significantly higher risk of postneonatal death and SIDS associated with macrosomia among births to First Nations women. This finding could be explained by the relatively small sample size of First Nations births in our study and hence, its limited power to detect moderate differences in death rates among birthweight subgroups. Alternatively, the observed differences could have been due to chance. Caution is particularly warranted when interpreting the elevated risk of SIDS among First Nations infants with macrosomia, given the small number of events.

The underlying causes of the observed high risk of postneonatal death and SIDS among macrosomic births to First Nations women are unclear. Impaired glucose tolerance and gesta- tional diabetes are frequent causes of macrosomia. ${ }^{15,24}$ One might speculate that abnormalities in maternal glucose metabolism in pregnancy could be an underlying cause. However, we are unaware of evidence linking postneonatal death or SIDS to diabetes in pregnancy. Type 2 diabetes and gestational diabetes are much more prevalent (two to three times higher than rates for the general population) in some First Nations communities in Quebec. ${ }^{25,26}$ Prevention-based programs to reduce the high prevalence of diabetes may help to decrease the rate of macrosomic births and perhaps also that of postneonatal deaths.

\section{Limitations}

We had no data on glucose tolerance and gestational diabetes. It would be worthwhile to explore whether impaired glucose tolerance and gestational diabetes are associated with postneonatal death and SIDS. We used maternal mother tongue to flag First Nations births. However, about $40 \%$ of self-identified Aboriginal women in Quebec did not report an Aboriginal language as their mother tongue, according to the 2001 census. Hence, a large number of self-identified Aboriginal women could have reported French as a mother tongue. However, such misclassifications would be unlikely to have affected the outcome rates for the much larger French-as-mothertongue group in the comparisons.

\section{Conclusion}

Parents and caregivers should be vigilant about the substantially elevated risk of postneonatal death among macrosomic infants of First Nations women. Further research is needed to understand the causal mechanisms and develop effective prevention programs.

\section{References}

1. Ananth CV, Wen SW. Trends in fetal growth among singleton gestations in the United States and Canada, 1985 through 1998. Semin Perinatol 2002;26:260-7.

2. Schack-Nielsen L, Molgaard C, Sorensen TI, et al. Secular change in size at birth from 1973 to 2003: national data from Denmark. Obesity (Silver Spring) 2006;14:1257-63.

3. Lahmann PH, Wills RA, Coory M. Trends in birth size and macrosomia in Queensland, Australia, from 1988 to 2005. Paediatr Perinat Epidemiol 2009;23:533-41

4. Surkan PJ, Hsieh CC, Johansson AL, et al. Reasons for increasing trends in large for gestational age births. Obstet Gynecol 2004;104:720-6.

5. Wen SW, Kramer MS, Platt R, et al. Secular trends of fetal growth in Canada, 1981 to 1997. Paediatr Perinat Epidemiol 2003; 17:347-54

6. Ananth CV, Wen SW. Trends in fetal growth among singleton gestations in the United States and Canada, 1985 through 1998. Semin Perinatol 2002;26:260-7.

7. Schack-Nielsen L, Molgaard C, Sorensen TI, et al. Secular change in size at birth from 1973 to 2003: national data from Denmark. Obesity (Silver Spring) 2006;14:1257-63.

8. Lahmann PH, Wills RA, Coory M. Trends in birth size and macrosomia in Queensland, Australia, from 1988 to 2005. Paediatr Perinat Epidemiol 2009;23:533-41.

9. Ehrenberg HM, Mercer BM, Catalano PM. The influence of obesity and diabetes on the prevalence of macrosomia. Am J 
Obstet Gynecol 2004;191:964-8.

10. Surkan PJ, Hsieh CC, Johansson AL, et al. Reasons for increasing trends in large for gestational age births. Obstet Gynecol 2004;104:720-6

11. Young TK, Sevenhuysen G. Obesity in northern Canadian Indians: patterns, determinants, and consequences. Am J Clin Nutr 1989;49:786-93

12. Harris SB, Caulfield LE, Sugamori ME, et al. The epidemiology of diabetes in pregnant Native Canadians. A risk profile. Diabetes Care 1997;20:1422-5.

13. Rodrigues S, Robinson E, Gray-Donald K. Prevalence of gestational diabetes mellitus among James Bay Cree women in northern Quebec. CMAJ 1999;160:1293-7.

14. Liu J, Hanley AJ, Young TK, et al. Characteristics and prevalence of the metabolic syndrome among three ethnic groups in Canada. Int J Obes (Lond) 2006;30:669-76.

15. Rodrigues S, Robinson EJ, Kramer MS, et al. High rates of infant macrosomia: a comparison of a Canadian native and a non-native population. $J$ Nutr 2000;130:806-12.

16. Caulfield LE, Harris SB, Whalen EA, et al. Maternal nutritional status, diabetes and risk of macrosomia among Native Canadian women. Early Hum Dev 1998;50:293-303.

17. Armstrong IE, Robinson EJ, Gray-Donald K. Prevalence of low
ARS MEDICA AND CMAJ ARE PLEASED TO CO-SPONSOR

\section{A Humanities Poetro} AND PROSE CONTEST

BASED ON THE THEME OF THE 2OIO CANADIAN Conference on Medical Education White Coat, Warm Heart: Integrating Science and Humanism

Submit your previously unpublished poetry ( 52 lines) or prose (maximum of 1500 words) for a chance to win a

one-year subscription to ARS Medica and publication in either CMAJ or ARS Medica.

Complete information at: www.cmaj.ca/home/humanities.dtl

Deadline: April 5, 20 II

\section{CMAJ Ars Medica}

and high birthweight among the James Bay Cree of northern Quebec. Can J Public Health 1998;89:419-20.

18. Luo ZC, Wilkins R, Platt RW, et al. Risks of adverse pregnancy outcomes among Inuit and North American Indian women in Quebec, 1985-97. Paediatr Perinat Epidemiol 2004; 18:40-50.

19. Luo ZC, Senécal S, Simonet F, et al. Birth outcomes in the Inuitinhabited areas of Canada. CMAJ 2010;182:235-42.

20. Kramer MS, Liu S, Luo Z, et al. Analysis of perinatal mortality and its components: Time for a change? Am J Epidemiol 2002; 156:493-7.

21. Kramer MS, Platt RW, Wen SW, et al. A new and improved population-based Canadian reference for birth weight for gestational age. Pediatrics 2001;108:E35.

22. Luo ZC, Wilkins R. Degree of rural isolation and birth outcomes. Paediatr Perinat Epidemiol 2008;22:341-9.

23. Armstrong IE, Robinson EJ, Gray-Donald K. Prevalence of low and high birthweight among the James Bay Cree of northern Quebec. Can J Public Health 1998;89:419-20.

24. Ehrenberg HM, Mercer BM, Catalano PM. The influence of obesity and diabetes on the prevalence of macrosomia. Am J Obstet Gynecol 2004;191:964-8.

25. Rodrigues S, Robinson E, Gray-Donald K. Prevalence of gestational diabetes mellitus among James Bay Cree women in northern Quebec. CMAJ 1999;160:1293-7.

26. Legare G. Project of diabetes surveillance among the Cree of Eeyou Istchee. Québec (QC): Institut de National Santé Publique du Québec; 2004. Available: www.inspq.qc.ca/pdf/publications1317-DiabeteCri_Ang.pdf (accessed 2010 Aug. 25).

Affiliations: From the Department of Obstetrics and Gynecology (Wassimi, Xiao, Simonet, Luo), Sainte-Justine Hospital, University of Montreal, Montréal, Que.; Health Analysis Division (Wilkins), Statistics Canada, Ottawa, Ont.; Department of Epidemiology and Community Medicine (Wilkins), University of Ottawa, Ottawa, Ont.; and First Nations of Quebec and Labrador Health and Social Services Commission (Mchugh), Wendake, Que.

Contributors: Spogmai Wassimi, Russell Wilkins and Zhong-Cheng Luo conceived the study. All of the authors contributed to the design of the study and the interpretation of the data. Zhong-Cheng Luo and Russell Wilkins analyzed the data. Spogmai Wassimi, Fabienne Simonet and Lin Xiao were involved in the literature review. Spogmai Wassimi and Zhong-Cheng Luo drafted the manuscript, and Russell Wilkins and Zhong-Cheng Luo revised it. All of the authors critically reviewed the manuscript for important intellectual content and approved the version submitted for publishing.

Funding: This study was supported by a research grant from the Canadian Institutes of Health Research, Institute of Aboriginal Peoples' Health (CIHR-IAPH, grant no. 73551).

Acknowledgements: The authors are grateful to Statistics Canada and the Institut de la Statistique du Québec for providing access to the data for the research project. Spogmai Wassimi was supported by a studentship from the research grant, Fabienne Simonet by a scholarship from the CIHR Strategic Training Initiative in Research in Reproductive Health Science (2008-2010) and from the Quebec Training Network in Perinatal Research (2010-2011), and ZhongCheng Luo by a Clinical Epidemiology Junior Scholar Award from the Fonds de Recherche en Santé du Québec, and a CIHR Gender and Health New Investigator Award. 